\title{
Kedilerde kronik böbrek yetmezliğinde kan nitrik oksit düzeyinin belirlenmesi
}

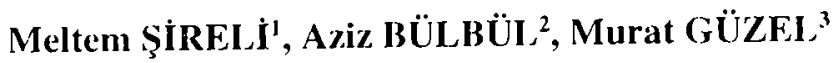

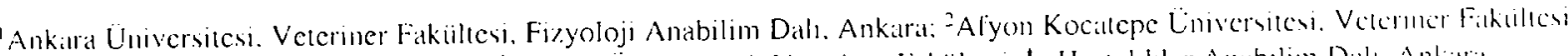

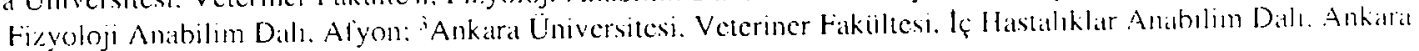

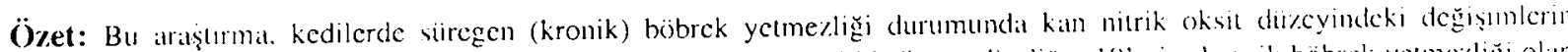

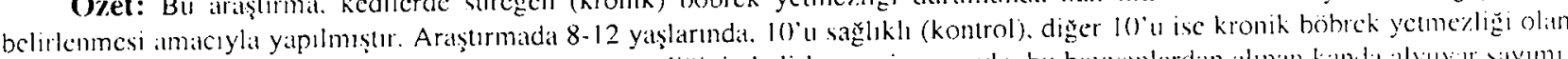

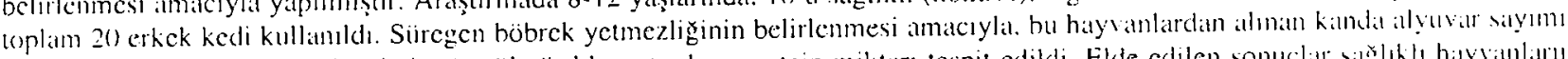

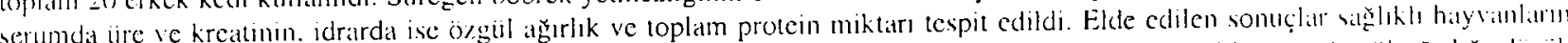

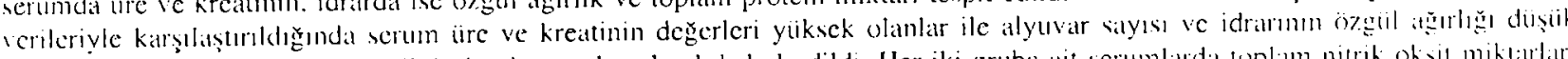
bulumanliar kronik böbrek yemęliŏg olan hayvanlar olitrak kabul edildi. Her iki grubal ait scrumlarda loplam mitrik okvil mikliarlar

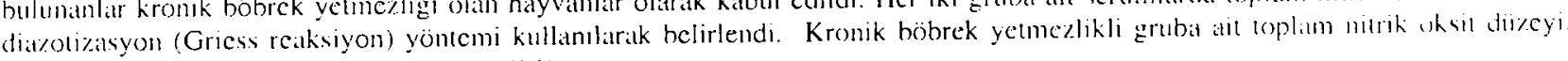
kontrol grubuna gore diișïk bulundu $(p<0.0(0) 1)$.

Anthtar kelimeler: Kcdi, kronik böbrek yctmezliügi, nitrik oksit

\section{The determination of blood nitric oxide levels in cats with chronic renal failure}

Summary: The present study aims to determine the differences in the blood nitric oxide levels of cats in calse of chronic renal failure. In the rescatrch. the number of male calts aging $8-12$ years were made up 20 as ten of them the nomat. healthy animals

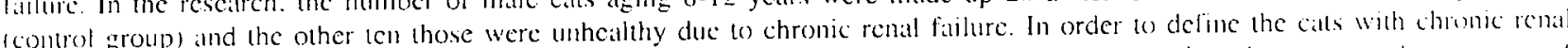
fialure. their blood and urine examinations were made to see any ahnormatities in the number of erythrocyes an the atmounts of serum ureat creattinine and urine total protein and also urine specific gravity. According to these meisurements. the animals were iecepted as unheallhy with chronic renal failure. which had higher amounts of serum urea and creatinine and lower villucs in the urine specific gratity and blood erythrocytes when compared to reference values of nomal healthy cats. The lolit nitlic oxicte level in the serum tatken from (wo groups were measured by using diazolization method (Griess acaction). It is found that the mean of the (otal nitric oxide levels of cats with chronic renal failure were significantly decreased compared to that of the contiol gloup $(p<() .()() !)$.

Key words: Catl. chromic remal latilure, nitric oxide

\section{Giriş}

Canlıda metabolizma artiklarmn vücutlan tızaklaşuırıması ile iç ortamın değ̈işnez tutulmasında yaşanısal rol oynayan böbrckler. aralarında eritropoietin ve re ninin de sayılabilece ğ çok sayıda hormon ve enzim üreliminde lonksiyonel görev üstlenmiştir (5).

Böbreğin normal işlevini sürdürme.: için; böbrek atardamarlar1, makula densa. glomeriil ve tubüllerde nitrik oksidarlann kolaylaşurucı etkisi ile L-arjininden olusan nitrik oksit gercklidir. Nitrik oksit (NO), böbrek otoregülasyonu. tubiiloglomerüler geribildirim, renin salunm, basinca bağlı sodyum geri çıkarılmasi, böbrek kan basmen ve tubül işlevlerinin düzenlenmesine yardme olur. Bunun yanunda, afferent arterioller üzerine oldukça güçlii damar genişletici ctki yapar (8). Arteriel basınç üzcrindeki aruş doğrudan ubiiller iizerine etkiyerek sodyum geri emilimini durduran endotel kaynaklı nitrik oksit oluşumunun artmasına yol açar. Bu etkinin nitrik oksidin renin salınımını azaltarak oluşturduğu tespil codilnușiti (8.29).

Vücutta f̧eşilli hücrelerde oluşan nirrik oksit. li\%. yolojik işleveri denetleyen nörotransmiter hir madkledir $(12,24)$. Memeli hücrelerinin bijolojik açıdan clkin salg̣ ürünleri arasında en düşük molckiil ağ NO hiicre zanndan kolilylıkla difize olahilir (23). Nitrik oksit, yağda çözinen ve hem if̧eren promeinlerin demir kısnuyla huzla tepkime oluşurur. Nitrik oksil oluṣumunal katılau enzim grubunum adı nitrik oksit sculak (N()S) du NOS, I-arjininden NO oluş(urän nikotinamid adenin dinükleotid fosfat (NADPH) a bağgmh bir deoksijenardu (17.29).

Nitrik oksit sentaz enzininin dizenleme ve elkinlik yönünden yapısal veya uyarılabilir olarak ilate edilen iki izomeri vardu (16.20.34). Yapısal olarak ilide coliten (cNOS), beyin ve endotel hiicrelerinde sürekli. liakal ctkin olmayan şekilde hulunan NOS'tur (10). Yapusal kit- 
raklerde nitrik oksit oluşumu için NADPH ve $\mathrm{Ca}$ kalmodilin'e gereksinim vardır $(20,26,28)$. Nitrik oksit sentazın uyarılabilit olarak adlandırılan şekli (iNOS) ise endocel huicrelerinde, makrofajlarda, nötrofillerde, karaciğer hücrelerinde ve damar düz kas hücrelerinde tespit edilmiş olup, normal koşullarda yoktur. Endotoksinler interferon-gamma, tünör nekroz faktör (TNF) gibi sitokinler tarafundan verilen uyanlar iNOS'un nitrik oksit ürctimini ctkin hale getirir. Uyarılnış olan NOS'un etkinliği kalsiyuma bağımlı olmamakla beraber NO oluşumu için NADPH ve letrahidrobiopterine gereksinim duynakladır. Uyarmm sonucunda oluşan nitrik oksit etkinliği cNOS’un ürettiği nitrik oksitin yüzlerce katı olup etkisi 4-24 saat kadar suirmektedir $(15,20,29,32)$.

Kronik böbrek yetmezliği glomeruiler filtrasyon oramunın azalması sonucunda oluşan azot artıklarının kanda birikmesi olarak ifade edilir $(5,9,11)$. Süregen böbrek yetme\%liğ oluşturan nedene bağlı olmayı, nefronlarda işlev kaybı ile ortaya çıkan geri dönüşüinsüz bir hastalıktır (7). Hayvanlarm kronik böbrek yetnezliğinde klinik bulgular erken dönemde orta olçiide poliüri, polidipsi, ağırlık kaybı ve kıl örtuisünde bozukluk, ileri dönemlerde ise iṣlahsızlık. depresyon, şiddetli ağırlık kaybı, kusma, sürgiin. dilde nekroz ve nukozalarda solgunluktur. Laboraluvar bulgular olarak ise serum üre ve kreatinin değcrlcrinde artış, idrarın özgüil ağırlığında azalma ve proteiniri tespit edilir (22). Süregen höbrek yetmezliğinin ortaya koyduğu en önemli etki, böbreklerin nefron bazında ǐcrine duişen yüklerinde artı̧̧a ayak uyduranıaması sonucunda idrarm tam olarak diluic edilemeden çok kısa suirede dışarı atılmasıdır. Karnivorlarda kronik böbrek yetmezliğj oldukça sık gö̈lemlenen bir hastalık olup, gencl olarak nedenleri arasinda ise kronik glomerulonelril. polikistik böbrek. taş ve prostat hipertrofisi sonucunda idrar yollammn tikanması ve lenfoma yer almakladir (5,.33)

Kronik böbrek yetmezliği hastalığına yakalanmış kedilere ait literatiir taramalarında oldukça kapsamlı klinik ve laboratuvar bulgularına rastlanılmasına karşın (1.7.22), böbrek otoregülasyonunda önemli rol oynadığ son on yıl içinde orlaya çıkarılan toplanı nitrik oksit düzeyindeki değişinıler hakkında bilgi bulunmamakladır. Bu kapsanda araşturmada kronik böbrek yetersizliğj belirlenen kedilerde toplam kan nitrik oksit dïzeyinin belirlenmesi amaçlanmıştır.

\section{Materyal ve Metot}

Bu araşurmada, Ankara Üniversitesi Veteriner Faküiltesi, Iç Hastalıklar Anabilinı Dalı'na getirilen 8-12 yaşlarında, 10'u sağlıklı. 10'u kronik böbrek yetmezliği olan toplan 20 erkek kedi kullanıldı. Kronik böbrek yet- mezlikli gruptaki hayvanlarda anoreksi. depresyon, poliüri, polidipsi ve kusma şikayetlerine ek olarak fiziksel muayeneleri sonucunda da deri elastikiyelinin kiybolduğu, tuiy yapısının kanşık. nukozalarm isc anemik olduğ gözlendi.

Hayvanlardan antikoagulansi\% tiiplere alınan kinn orneklerinden elde edilen serumlarda iure, kreatinin (35). idrarda ise toplam protein (19) ve öguil ağurlık değerleri ile EDTA'h tüplere alınan kanlarda alyuvar sayıss belirlendi. Kronik böbrek yetmezliği bulgulan gösleren kedilerin kanları, kronik böbrek yelnc\%likli (KBY). sağliklı hayvanların kanları ise kontrol grubu olarak alylild.

Her iki gruptaki hayvanlarm serum irnek!cri $-18^{\circ} \mathrm{C}$ derecede sakland. Bu serumlarda nitrik oksit miklar belirlenmesinde diazotizasyon (Griess reaksjyon) yöntemi kullanıldı (18). Bu yönteme göre $\mathrm{H}_{3} \mathrm{PO}_{4}$ ü $\% 85$ lik çözeltisinden \%2.5 lik çözeltisi suda hazıland. "\%2.5'luk $\mathrm{H}_{3} \mathrm{PO}_{4}$ içinde, suilfanilamid $\% 1$ ve $\mathrm{N}$-( I-naftil) etilendiamin (NEDD) \%:0.1'lik olacak şekilde çözdüruildii. Diğer

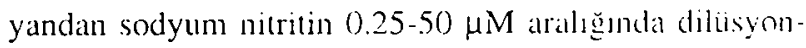
ları oluşturuldu ve buna göre kalibrasyon eğrisi hakrland (Şekil 1) (34).

Her iki grubun serumlarmdan $1.5 \mathrm{ml}$ alund ve izerlerine $0.75 \mathrm{ml}$ sülfanilamid ve $0.75 \mathrm{ml}$ NEDD çörclissi eklendi. Oda sıcaklığında 15 dakika beklctildikıen sonma spektrofotometrede $550 \mathrm{~nm}$ 'de okundu.

Kontrol ve kronik höbrek yeinuclikli grup arasındaki değer farklılıkları studen "i" lesti kullamılarak belirlendi. (MS Windows için SPSS 9.0 pakee progranı).

\section{Bulgular}

$\mathrm{Bu}$ araştırmada kontrol ve kronik böbrek yetme\%liğ j olan gruptan elde edilen kan, üre, kreatinin değgerleri. alyuvar sayıları ve idrarda ögiil agrlık diizeyleri Tablo l'de. kan nitrik oksit değgerleri ise Sekil 2 de verildi

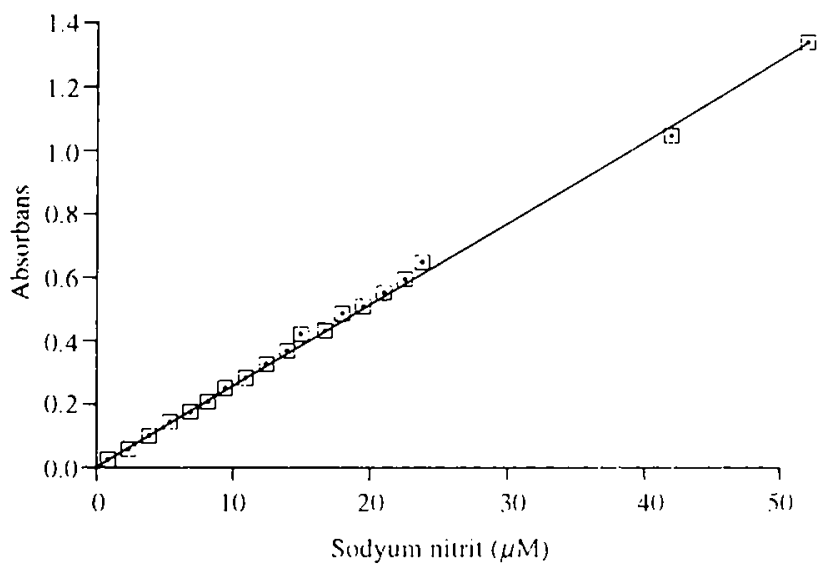

Şekil 1. Sodyum nitrit konsintrasyonlarma karș okunim absorbans de gerleri ile elde edilen kallibrisyon c.̆grisi.

Figure 1. The calitration curve obtained by absorbance read against the concentrations of sodium nitrite. 


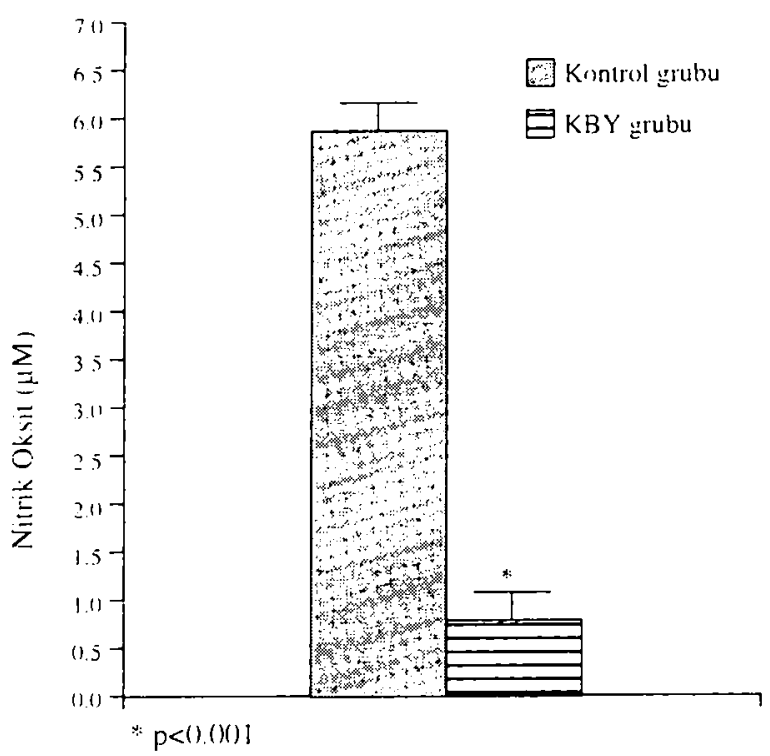

Sckil 2. Siţ̌lıklı (kontrol grubu) ve kronik böbrek yetmezligi olan (KBY grubu) kedilerde kan nitrik oksit diizeyleri ( $\mu \mathrm{M})$. Histograın aritmetik ortalamat ve standart hatayı göstermekte olup. $n=10$ dur.

Figure 2. The levels of blood nitric oxide $(\mu \mathrm{M})$ in the healthy cats and those with chronic renal fiilure. The histogram shows the mean and standart error and $n=l 0$.

Tablo I. Siağ liklı (kontrol grubu) ve kronik böbrek yctmezliğgi olan $(K B Y$ grubu) kedilerde kan iirc (mg/dl). kreatinin ( $\mathrm{mg} / \mathrm{dl}$ )

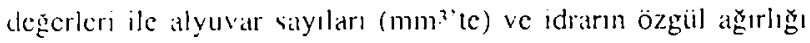
değericri.

Table 1 . The valucs of blood urcal ( $\mathrm{mg} / \mathrm{dl})$, creatinine $(\mathrm{mg} / \mathrm{dl})$, red blood cell (mmi) and urine specific gravity in the healthy cills and those with chronic renal failure.

\begin{tabular}{|c|c|c|}
\hline & $\begin{array}{c}\text { Kontrol grubu } \\
\begin{array}{c}X \pm S X \\
(n=l(1)\end{array}\end{array}$ & $\begin{array}{c}\text { KBY grubu } \\
X \pm S X \\
(n=1(1)\end{array}$ \\
\hline Ure $(m g / d l)$ & $31.72 \pm 2.69 *$ & $275.7 \pm 46.12$ \\
\hline Kreatinin $(\mathrm{mg} / \mathrm{dl})$ & $0.85 \pm 0.05^{*}$ & $5.73 \pm 0.96$ \\
\hline Alyu'ar sayisi (mm? & $645500\left(1 \pm 256.75^{*}\right.$ & 3() $850(K) \pm 185.94$ \\
\hline 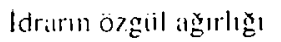 & $1.045 \pm 0.0002^{*}$ & $1.011 \pm 0.0001$ \\
\hline
\end{tabular}

$* p<(1)(0) 1$

Kronik böbrek yetmc\%liğgi olan grup kontrol grubu ile karşılaşurıldığ $(p<0.001)$, loplam nitrik oksil dijzeyi, alyuvar sayısı ve idrardaki özgìl ağırlık değerleri dưşük ve aralarındaki fark istatistik açıdan önemli $(p<0.001)$ bulundu.

\section{Tartışma ve Sonuç}

Araşurmada kedilerde kronik böbrek yctmezliğinin belirlemmesi anlaciyla kan üre, kreatinin değerleri ve alyuvar sayılars ilc idrardaki özgìl ağırlık değerlendirilmiş, elde edilen sonuçlar doğrultusunda sağlıklı hayvanlara (kontrol) göre istatistik yönden anlamlı bulunan veriler kronjk böbrek yetmezlliği olarak kabul edilmiştir. Ke- dilerde kronik böbrek yetmezliğinin değgerlendirilnesinde Deguchi ve Aku\%awa (14). Börkii ve alk. (7). Adams ve ark. (1)'nun bildirdiği serum üre ve kreatinin değgerlerinde artış ile idrar özg̨iil ağırlığgndaki azalışın belirlenmesine öncelikle dikkat edilmiştir. Nitckim, laboraltuvar anatlizleri sonucunda kronik böbrek yetmezliği tamssı konulan hayvanlarda serum üre ve kreatinin degererleri slrasiyla $257.7 \pm 46.12 \mathrm{mg} / \mathrm{dl} .5 .73 \pm(0.96 \mathrm{mg} / \mathrm{dl}$ olup $\mathrm{kon}$ trol grubuna göre (sağlıklı) yüksek. idrarda belirlenen ij/guil ağ

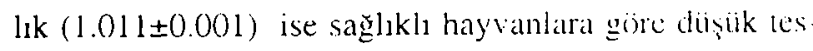
pit edilnıştir. Söz konusu araşırıcılar (1.7.14). kromik böbrck yetmezlikli kedilerde scrum üre, kreatimin ve id rardaki özgül ağğrlık sırasıyla $136.7 \mathrm{mg} / \mathrm{dl} .5 .09 \mathrm{mg} / \mathrm{dl}$. 1.009 olarak belirlemişlerdir.

Yine klinik açıdan kedilerde kronik höbrek yet. mezliği bulgularndan biri olarak literatuirde bildirilen (27) ve böbrekten salman eritropoiclinin hormonunum azalması sonucunda ortaya çıkan anemi durumu da gioz önuinde tutularak hayvanların kanlarında alyuvar sayıları belirlenmiş, hüicre sayılarındaki düişikliik araşırma ön cesinde ölçüt olarak alınmışur. Diğer yandan. kronik böb rek yetmezliğgi nedeniyle organm görevini lam olarak y'a pamaması sonucunda normalin 3 hatla 20 katullal frkabilen idrarla birlikte tam olarak sijziilmeden bol miklirdal protein de atslmakla ve albiiminiriye neden olmakiadu (13.20). Bu yüzden idrarda proteinjn göriilnesi haslallğgn belirlenmesinde önemli bir yer tummuştur.

Böbreğin oloregülasyonunun hozulmasinda ckin birçok faktörden söz açılırken dikkat edilmesi gereken en önenli noktalardan birisi, belki de organ ve dolayısiyla tiim viicudu etkileyebilecek böbrek kalynaklı hormon ve enzim diizeylerindeki değişmelerdir. Bu kilpsamda son yıllarda organizmada çok önemli rol oynadığ belirlenen nitrik oksit (8) diizeyinde de teğişimler olmass kat çmılmaz göruildïğinden, araşurmada kronik böbrek yetmezliğ belirlenen kedilerin scrum nitrik oksil diizyi sağlıklı hayvanlarınki ile karşlaş̧ı momş̧ur. Bulgularda. sağhklı hayvanlardaki kan nitrik oksil diisyi ortalima $5.84 \pm 0.38 \mu \mathrm{M}$ olarak belirlenirken, kronik boibrek yelmez.likli hayvanlarda bu değer ortalamal $0.86 \pm 0.15 \mu \mathrm{M}$ olarak tespit edilmiştir. Elde edilen bu sonuça ka kontrol ile karşılaşurıldı̆̆ında Angelini ve ark. (2) nun sonuçları ile benzerlik göstermektedir. Bahsi geçen arașlutulat, insanda kronik böbrek yemezliğinde plazma nitrik oksil düzeyini $(12.4 \pm 4.0 \mu \mathrm{nol} / \mathrm{L})$ kontrol guthuma goire $(64.6 \pm 5.7 \mu \mathrm{mol} / \mathrm{L})$ istatistik anlanda diişïk bulmușlardır. Ayrica, organda meydana gelen tararm hipertansiyonlat sonlanabileceğmi ve yetersiz. NO'nun da hipertansiyon oluşununda etkin rol oynalyabileceğgini bildirmişlerdir. 
Morris ve Jardine (25). damar genişletici elkili nitrik oksit oluşumunun az olması nedeniyle, hipertansiyon ve alcroskleroz oluşumunda anahtar görev üstlenebilece ği. dolayısıyla da katp-damar hastalığmın kontrolünde kronik böbrek yelmezliğgnde göo önünde lutulması gerektiğini vurg̣ulamışlardı. Yine kronik böbrek yekersizliğinde hipertansiyon oluşumunda sempatik sinir elkinliğinde arışın oluştuğ (6,10), bu artışn nedeninin ise merkezsel sinir sistemi elkinliğini inhibe eden NO üretimindeki azalma olabilece ği bildirilniştir (31).

Araşırmadlal. kronik böbrek yetmezliği olan gruptan elde edilen toplan mitrik oksit diireyindeki değişimle. harzı araşımmacularm $(3,21,30)$ idrar nitrik oksit dïzeyinde belirledikleri azalma ile benzerlik gösterirken, Kim ve ark. (21)'nun kronik böbrek yetmezligi olan s1çanlarda belirledikleri plazma nitrik oksil duzeyi bakımundan farklılık göstermekıcdir. Sïzü edilen araşturıcı. lar kronik böbrek yelmexliğinde plazma NO düzeyinde değişim belirlemeaken, NOS izomerleri olan iNOS ve cNOS un hayanlarm glomerüllerinde salmmmin azaldı̣̆nı bildirmekıedirler. Ancak. I-arjininden NO oluşumunda görev alan NOS en/im grubu etkinliğgindeki azalma nedeniyle. NO miktarnda da azalma görïlmesinin kaçmılmaz olacağ bildirilmektedir (1.4). Yine Noris ve Rcmuki (26). böbrek iN(OS daki azalma sonrası glomerüler fillasyon. lübüler geri emilim ve renin üretiminden sorumlu NO dücyinin. sağlıklı sıçanlara göre böbrek yęmoxliĝ̣nde diiş̧ik olduğ ve dolayısıyla NO oluşumunum böbrek örselenmesi ile ters ilişkili olduğunu bildirmektedir.

Sonuç olarak. bu araştırmada, kedilerde kronik böbrek yetmezliğinde toplam nitrik oksit duzeyi sağlıklı hayvanlara göre diişük bulunmuş, bu bulg̨unun farklı birçok nedenden oluşabilen kronik böbrek yemezlighinin değerlendiribnesinde önemli bir yer tutacağ kanısma van.ılmışıtr.

\section{Kaynaklar}

1. Adams LG, Polzin DJ, Osbornc CA, O'Brien TD) (1994): Effects of dietary protein and calorie restriction in dinicalls normal cats and in cats with surgically induced chromic renal failure. An J Vet Res. 55. 308.

2. Angelini D, Parrini M, Carlini A, Fiorini L, $\Lambda$ ntonelli $A$ (2(1)1): Endothelin and nitric oxide balance: comparison between essental hypertensive and chromic renal failure patients. Am J Hypertension. 14. P98.

3. Arai J, Kubota $K$, Hara $Y$, Tsuchiya $K$, Naruse $K$, Naruse $\mathbf{M}$, Nihei $\mathbf{H}$, Sugino $\mathbf{N}(2)(0)$ ): Natriuresis and blood pressure in patients with chronic renal failure following $L$ arinine infusion. Nippon Jinzo Gakkai Shi. 42.11-15.
4. Arese M, Strasly M, Ruva C. Costamagna C, (ihido D), MacAllister R, Verzetti G, Tetta C, Bosia $\Lambda$, Busolino F (1995): Regulation of nitric oxide sumbesis in artemice. Nephrol Dial Tramsplant. 10. 1386-1397

5. Bainbridge J, Elliott J (1996): BSAY'A Memeal of Canime

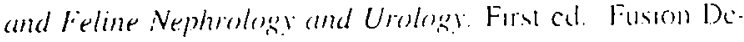
sign, Fordingbridgc. Hants.

6. Boreo R. Pignataro A, Ferro M. Quarelo l: (?(1)1) Sympathetic nervous system and chrmic renal failure. Clon Exp Hyperiens, 23,69-75

7. Börkü KM, Kurtdede $\Lambda$, Aydın Y, Durgut R. Pelikiaya

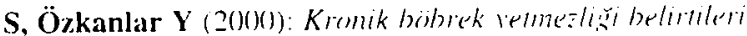

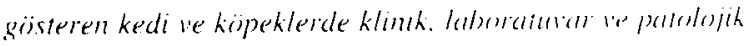
bulgular: Ankiaril liniv Vel Fik Dorg. 47. 281-289)

8. Braam 13 (1999): Renal endentetial and mac ula dertsa

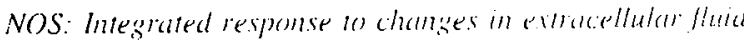
volume. Am J Physiol. 276. R155I R1561.

9. Brenner BM, Meyer TW, Hostetter IH (I)82): Dirfary protein intake and the progessive nature of remal disease. The role of hemodyamically mediated ghomendar injury

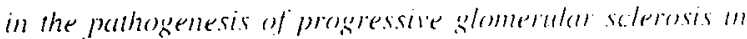
ageing. renal ablation. and intrinsic renal disease. New England J Med, 307, 652

10. Campese VM (20)(0)): The kidnel and the newrosenic comtrol of hloind pressure in renal disease. I Vophrologs. 13 221-224.

11. Clermont G, I cecour S, Lahet J.J. Siohan P, Vergely C. Chevet D, Rifle (i, Rochette I, (20)1): Alteration in plasma antioxidan capacities in chronic renal failate and hemodialysis patients. Clin Nephrology, 55. $4611-464$.

12. Coleman JW (20)1): Nirric oride in immoming and in/lammation. Int Immunopharmatcol, 1, 1.39?-i+1)6.

13. Cowgill LD, James KM, Levy IK, Browne JK. Willer A, Lobingier RT, ligrie JC (1998): Use of recombintm human engthroponetin for management of anemia in des.s. and cats with renal failure. Am Vet Med Asooc, 212. 521528

14. Deguchi E, Akuzawa M (1997): Renul clearance of en dogenous creatinine. urea sodiam. and potassium in nurmal cats and cats with chromic renal fuilure. J Vor Mod Sci. 59. $5(1)-512$.

15. Durante W, Liao L, Schafer $\mathbf{A l}$ (1995): Diflemential te sulation of L-arainine transpont and indacible NOS in aullured bascular smooth muscle cells. Am J Physiol. 268. HII58-H1164.

16. Editorial (1997): Nitric ovide determincianms: Much ades about NO-thing? Clin Chem, 43. 553-555

17. Förstermann U, Schmidt $\mathrm{AHW}$. Pollock JS. Slicng $\mathrm{H}$, Mitchell JA, Warner TD, Nakane M, Murad F (199)

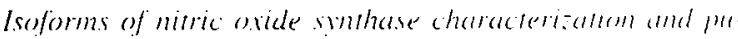
rification from different cell npes. Bioc Pharm. 42. 1849) 1857.

18. Green LC, Wagner DA, Glogowski J, Skipper P', Wis-

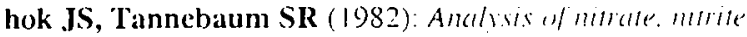
and /'sN/ nitrate in bislegical fluids. Antalytical B10c. 126 $131-138$

19. Grodwohl RBH (1950): Clinical Labanatory Meihud and Diagnesis. Vol. 1. 5in ed. The CV Moshy Co. St. Louis 
21). Joly GA. Schini VB, Vanhoutte PM (1992): Balloon infun and interleukin-l $\beta$ induce nitric oxide symthase acmin in rat carotid arteries. Circulation Res, 71, 331-338.

21. Kim SW, Lee J, Kang DG, Jung K, Kim NH, Suh SP, Choi KC, Kang Y.J (20(0)): Erythropoietin does not affect nitric sxide sistem in rats with chronic renal failure. J Korean Med Sci. 15. 183-188

22. Kurtdede $\Lambda$, Börkü MK (1998): Uriner Sistem Has latıklart: Kedi re Koipek Hastalkklart. 2. Batski. Medisan Yalymeri. Ankarit.

23. Manukhina EB, Malyshev IY, Smirin BV, Mashina SY, Saltykova VA, Vanin AF (1999): Production and storage of nitric oxide in adaptation on hypoxia. Nitric Oxide: Biol Chem. 3. 393.40)1

24. Moorcroft M.J, Davis J, Compton RG (2001): Detection and determinatum of nitrate and nitrite: a review. Talanlat. 54. $785-8113$

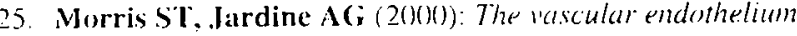
in chromic renal foilure. J Nephrol, 13,96 105.

26. Noris M, Remuzzi (; (1999): Physiology and pathophvisilogy of nitric oxide in chronic renal disease. Proo Assoc Am Physicians. 111. 6(12-610.

27. Pechereau D), Martel P, Braun JP (1997): Plasma enthropoletin concentrations in degs and cats: reference values and changes with anaemia and/or chronic: renal failure. Res Vot Sci, 62. 185-188.

28. Radomski MW, Palmer RM.J, Moncada S (199()): Glucrecorricosids inhibit the expression of an inducible, but hot the comstimutive, nitric: oxide symhase in vascular endonthetial cells. Proc Natl Acad Sci. 87, 10(1)43-10047.
29. Rodeberg DA, Chaet MS, Bass RC. Arkovit\% SM. Gorcia VE (1995): Nitric oride: An onerriew: Am J Sulgery. 170. 292-303.

30. Schmidt R.J, Baylis C (2000)): Totel nitric ovide pro. duction is low in patients with chronic rental disease. Kidney In. 58. 1261-1266

31. Shaohua Y, Nosrati S, Campese V.M (1997): Virric aride (NO) modulates the newogenic control of blend pressure in rats with chromic renal failure (CRF) I Clin Invest. 99 $54(1-548$

32. Stuehr D.J, Marletta MA (1985): Mammedent mirche hosynthesis: Mouse macrophuteses produce nitrte and nitrote in response to Escherichia coli lipopolvaracharde. Prox Natl Acad Sci. 82. 7738-7742

33. Torunoğlu M (1972): Biblirek Hatstalthlartander Biobsieh

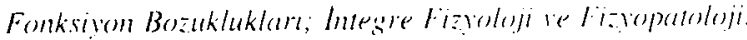
Atatirk C̈niv Basimevi. Erzurum.

34. Tunçtan B, Uludağ O, Altuğ S, Abacooğlu Xi (19)8): /:-

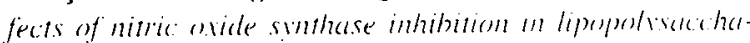
ride-induced sepsis in mice. Pharm Res. 38. $415-411$.

35. White WI, Erikson MM, Stevens SC (197(1): Chemism for the Clinical Luberanery. fll ed. The CV Mosby Co. Si Louis.

Geliş turihi: 9.10.2001/Kahul turiht:31.10.2001

Yazışma adresi:

Doç. Dr. Mellem Şireli

Ankara Üniversitesi

Veteriner Fakiallesi

Fizwoloji Anubilim Dall

OKllo Diskalm. Ankara

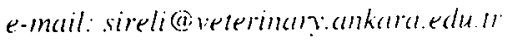

